\title{
Local Anesthesia in Oral and Maxillofacial Surgery
}

\author{
Reena Rachel John
}

\subsection{Introduction}

Pain, the dreaded symptom, is an unpleasant sensation that draws the attention of the individual as a whole. Its management has greatly evolved in the field of dentistry, starting from the leaves of a coca tree to articaine, Comfort Control Syringe (CCS) system, Transcutaneous Electrical Nerve Stimulation (TENS), Computer-Controlled Local Anesthetic Delivery System as well as oral and intravenous sedatives. Apart from all these, local anesthesia (LA) is the favored mode of pain control in the profession. The painless surgery under LA is must; otherwise, endogenous catecholamines are released if there is excessive pain during dental treatment, which can alter the hemodynamic status such as an increase in blood pressure and heart rate and even dysrhythmias [1].

\subsubsection{Historical Background}

The first local anesthetic isolated from the leaves of a coca tree in 1860 by Neiman was cocaine, and it was Karl Koller in 1884 who showed the anesthetic effect of Cocaine. In 1905, Einhorn popularized Procaine as an effective local anesthetic. It was derived from benzoic acid and diethyl amino ethanol. In 1948, the anesthetic property of lignocaine was discovered by Lofgren, and T. Gordh applied it in dental surgery [2].

\subsubsection{Definition}

Local anesthesia is defined as a reversible loss of sensation in the circumscribed area of the body caused by depression of excitation in the nerve endings or inhibition of the conduction process in peripheral nerves [2].

\subsubsection{Ideal Characteristic of Local Anesthesia}

An ideal local anesthetic must have the following characteristics:

- It should be nonirritating and nonallergic.

- It should not cause structural changes to nerve and have low systemic toxicity.

- Its onset of action should be short and should be stable in solution.

- It should be effective as both injectable and topical application.

- Its action should be long enough to allow the procedure to be completed.

\subsection{Classification (Tables 5.1 and 5.2)}

Table 5.1 Classification of local anesthetic agents: based on chemical structure

\begin{tabular}{|l|l|}
$\begin{array}{l}\text { Chemical structure } \\
\text { Esters of benzoic acid }\end{array}$ & $\begin{array}{l}\text { Example } \\
\text { Cocaine, Benzocaine, Butacaine, } \\
\text { Piperocaine, Tetracaine }\end{array}$ \\
$\begin{array}{l}\text { Esters of para amino } \\
\text { benzoic acid }\end{array}$ & $\begin{array}{l}\text { Procaine, Chloroprocaine, Propoxycaine } \\
\text { Amides }\end{array}$ \\
\hline Quinolome, Mepivacaine, Prilocaine \\
\hline Centbucridine
\end{tabular}

R. R. John $(\varangle)$

Department of Oral and Maxillofacial Surgery,

Vinayaka Mission's Sankarachariar Dental College and Hospital,

VMRF DU, Salem, India 
Table 5.2 Classification of local anesthetic agents: based on duration of action

\begin{tabular}{l|l|} 
Duration of action & Example \\
\hline $\begin{array}{l}\text { Ultra short acting } \\
\text { Pulpal anesthesia: less than } 10 \mathrm{~min} \\
\text { Soft-tissue anesthesia: } 30-45 \mathrm{~min}\end{array}$ & Chloroprocaine, Procaine \\
\hline $\begin{array}{l}\text { Short acting } \\
\text { Pulpal anesthesia: } 5-10 \mathrm{~min} \\
\text { Soft-tissue anesthesia: } 60-120 \mathrm{~min}\end{array}$ & Lidocaine, Prilocaine \\
$\begin{array}{l}\text { Medium acting } \\
\text { Pulpal anesthesia: } 45-90 \mathrm{~min}\end{array}$ & Mepivacine, Articaine \\
Soft-tissue anesthesia: $120-240 \mathrm{~min}$ & \\
$\begin{array}{l}\text { Long acting } \\
\text { Pulpal anesthesia: } 90-180 \mathrm{~min} \\
\text { Soft-tissue anesthesia: } 240-540 \mathrm{~min}\end{array}$ & Bupivicaine, Etidocaine \\
\hline
\end{tabular}

\subsection{Local Anesthetic Agents}

The LA agents have been divided into Esters and Amides groups. The commonly used Amides are Lidocaine, Articaine, and Bupivacain [2].

\subsubsection{Lidocaine (Lignocaine)}

Lofgren in 1943 introduced the prototype amide local anesthetic [2], i.e., Lidocaine.

The other similar names are xylocaine, octocaine, dentocaine. Chemically, it is Diethyl 2, 6 dimethyl acetanilide. The maximum recommended dosage for Lignocaine with vasoconstrictor is $7 \mathrm{mg} / \mathrm{kg}$ not exceeding $500 \mathrm{mg}$ and without vasoconstrictor is $4.4 \mathrm{mg} / \mathrm{kg}$ not exceeding $300 \mathrm{mg}$. Its onset of action is $2-3 \mathrm{~min}$ and duration of action with vasoconstrictor is $45-75 \mathrm{~min}$, without vasoconstrictor is less than $30 \mathrm{~min}$. Its contraindications include Ehlers Danlos syndrome and Attention-deficit hyperactive syndrome. Lignocaine is available in the form of jelly, spray, patches, and ointments. The toxicity arises from inadvertent intravascular administration or from overdose.

Recently, Howlader et al. [3] suggested open reduction and internal fixation (ORIF) of isolated subcondylar fractures under local anesthesia by using $2 \%$ lidocaine with 1:200,000 epinephrine for mandibular nerve block and superior cervical plexus blocks (SCPB).

To anesthetize the cutaneous branches of SCP (lesser occipital, greater auricular, transverse cervical, and supraclavicular nerve), the solution is deposited at the midpoint of the posterior border of sternocleidomastoid muscle border, as well as inferior and superior to that point subcutaneously creating a field block.

The anesthetic agent selection should be based on three main clinical considerations: anesthetic potency and latency, onset, and duration. The composition of the local anesthetic solution is shown in Table 5.3.
Table 5.3 Composition of local anaesthetic solution (Lignocaine with Adrenaline)

\begin{tabular}{|c|c|}
\hline Ingredients & Functions \\
\hline $\begin{array}{l}\text { Lignocaine } \mathrm{HCl} \\
2 \%(21.3 \mathrm{mg})\end{array}$ & Anesthetic agent \\
\hline $\begin{array}{l}\text { Adrenaline } \\
1: 80,000 \\
(0.0125 \mathrm{mg})\end{array}$ & $\begin{array}{l}\text { Vasoconstrictor, decreased absorption of LA in } \\
\text { blood }\end{array}$ \\
\hline $\begin{array}{l}\text { Sodium } \\
\text { Metabisulfite } \\
(0.5 \mathrm{mg})\end{array}$ & Preservative \\
\hline $\begin{array}{l}\text { Methyl Paraben } \\
(1.0 \mathrm{mg})\end{array}$ & Preservative to increase shelf life \\
\hline $\begin{array}{l}\text { Sodium Chloride } \\
(0.6 \mathrm{mg})\end{array}$ & Isotonicity of solution to the tissues \\
\hline $\begin{array}{l}\text { Sodium } \\
\text { Hydroxide }\end{array}$ & To maintain and adjust $\mathrm{pH}$ \\
\hline Thymol & Fungicidal \\
\hline Distilled water & Dilution \\
\hline Nitrogen Bubble & $\begin{array}{l}1-2 \mathrm{~mm} \text { in diameter, present to prevent oxygen } \\
\text { from being trapped in cartridge and potentially } \\
\text { destroying vasopressor or vasoconstrictor. }\end{array}$ \\
\hline
\end{tabular}

\subsubsection{Bupivacaine}

Its chemical name is 1 butyl-2,6piperoloxylidine hydrochloride.

It is four times more potent than prilocaine, lidocaine, and mepivacaine. It is less toxic than lidocaine and mepivacaine and it is metabolized in the liver by amidases and excretion via kidney $16 \%$ unchanged. Its onset of action is similar to lidocaine, mepivacaine, and prilocaine. Effective dental concentration is $0.5 \%$ and anesthetic half-life is $2.5 \mathrm{~h}$.

Maximum recommended dose is $1.3 \mathrm{mg} / \mathrm{kg}$ body wt to a maximum of $90 \mathrm{mg}$. Because of its long duration of action, it is advisable for use in lengthy surgical procedure and the management of postoperative pain. Hence, the patient's requirement for postoperative opioid analgesics is lessened when bupivacaine is used. Bupivacaine is not recommended in young patients as the risk of self-mutilation is increased.

The duration of soft-tissue anesthesia has been consistently shown to be longer than with lidocaine [4] and thereby reducing postoperative pain experience [5].

\subsubsection{Articaine}

Its chemical structure is 3-N Propylaminoproprionylamino 2-Carbomethoxy 4-Methylthiophene hydrochloride.

The potency of Articaine is 1.5 times more than lignocaine and 1.9 times than procaine. Its onset of action when used with vasoconstrictor is $1-2$ min. Half-life is approximately $21 \mathrm{~min}$ and it is metabolized to pharmacologically inactive metabolite called articaine acid glucoronide. Since it is rapidly biotransformed to its inactive metabolite, it is a safe local anesthetic agent. It is excreted via kidney 
Table 5.4 Maximum recommended dose of common Local Anesthetic used

\begin{tabular}{|c|c|c|c|}
\hline Local Anesthetic & $\mathrm{mg} / \mathrm{kg}$ & $\mathrm{mg} / \mathrm{lb}$ & MRD (mg) \\
\hline \multicolumn{4}{|l|}{ Articaine } \\
\hline With vasoconstrictor & 7.0 & 3.2 & 500 \\
\hline \multicolumn{4}{|l|}{ Bupivacaine } \\
\hline With vasoconstrictor & 1.3 & 0.6 & 90 \\
\hline \multicolumn{4}{|l|}{ Lidocaine } \\
\hline No vasoconstrictor & 4.4 & 2.0 & 300 \\
\hline With vasoconstrictor & 6.6 & 3.0 & 500 \\
\hline
\end{tabular}

unchanged (5-10\%) and as metabolite (90\%). The maximum recommended dosage for articaine is $0.8 \mathrm{mg} / \mathrm{kg}$ body weight.

Contraindications for the use of articaine are Idiopathic or congenital methemoglobinuria, hemoglobinopathies, hypoxia, and in patients with cardio-respiratory failures. Prolonged paraesthesia has been reported as a complication following inferior alveolar nerve block (IANB) [6].

Articaine with epinephrine is the best choice to improve anesthesia in both inflamed and in uninflamed tissues with good results, and more effective anesthesia for longer duration can be achieved [7]. Table 5.4 shows maximum recommended dose of commonly used LA.

\subsection{Vasoconstrictors}

Importance of vasoconstrictors in local anesthetic solution include

1. To decrease the tissue perfusion and therefore to decrease the blood flow at the site of drug administration, which further decreases the absorption of local anesthetics into the circulatory system. Therefore, the blood levels of the anesthetic agents remain low, thereby decreasing the risk of toxicity [2].

2. It also increases the time taken by the local anesthetic to be absorbed from the site of administration and therefore increases the duration of action of the local anesthetic.

Most commonly used vasoconstrictors are epinephrine, norepinephrine, levonordefrin hydrochloride, phenylephrine hydrochloride.

\subsubsection{Dilution of Vasoconstrictor}

The explanation of 1:1000 vasoconstrictor concentration is that $1 \mathrm{~g} / 1000 \mathrm{mg}$ of solute is present in $1000 \mathrm{ml}$ of the solution, which means $1 \mathrm{mg}$ of solute in $1 \mathrm{ml}$ of solution. In the local anesthetic solution, the concentration of vasoconstrictor is less. The concentrations used are $1: 80,000$ or $1: 100,000$ or $1: 200,000$. The concentration of $1: 100,000$ of the vasoconstrictor would contain $1000 \mathrm{mg}$ in $100,000 \mathrm{ml}$ of the solution. Therefore, $1 \mathrm{ml}$ of 1:100,000 concentration would contain $0.01 \mathrm{mg}$ in $1 \mathrm{ml}$.
Table 5.5 Quantity of vasoconstrictor with varying dilutions

\begin{tabular}{|l|l|l|l|}
$\begin{array}{l}\text { Concentration } \\
\text { (dilution) }\end{array}$ & $\begin{array}{l}\text { Milligrams per } \\
\text { milliliter }(\mathrm{mg} / \\
\mathrm{ml})\end{array}$ & $\begin{array}{l}\text { Micrograms per } \\
\text { milliliter }(\mu \mathrm{g} / \\
\mathrm{ml})\end{array}$ & $\begin{array}{l}\text { Microgram per } \\
\text { cartridge }(1.8 \\
\mathrm{ml})\end{array}$ \\
\hline $1: 1000$ & 1.0 & 1000 & \\
\hline $1: 2500$ & 0.4 & 400 & \\
\hline $1: 10,000$ & 0.1 & 100 & \\
$1: 20,000$ & 0.05 & 50 & 90 \\
$1: 30,000$ & 0.033 & 33.3 & 73 \\
$1: 50,000$ & 0.02 & 20 & 36 \\
\hline $1: 80,000$ & 0.0125 & 12.5 & 27.5 \\
$1: 100,000$ & 0.01 & 10 & 18 \\
$1: 200,000$ & 0.05 & 5 & 9 \\
\hline
\end{tabular}

The absorption of vasoconstrictors is dose dependent and may last from minutes to half an hour. The patients with cardiovascular compromise are at increased risk with endogenously released epinephrine in response to stress rather than the epinephrine, which is injected with the local anesthetic (Table 5.5).

\subsection{Causes of Failure of LA}

1. Anatomic variation

2. Bifid or double nerve supply

3. Secondary supply by a soft-tissue nerve

4. Inadequate dose

5. Injection into the blood vessel

6. Degradation of vasoconstrictor

7. Patient having sepsis

\subsection{LA Toxicity and Antidote for Toxicity}

Symptoms, which reflect toxicity from the administration of local anesthetic solution, may range from mild cutaneous reactions to severe life-threatening anaphylactic reactions. There are a variety of methods and drugs to treat these reactions symptomatically. However, the reversal of toxicity, including damage to vital organs such as the heart and brain, is still less understood. A clinically efficient antidote for a complete reversal of toxicity is still beyond our grasp currently.

\subsubsection{Reversal of Cardiomyotoxicity}

Intravenous lipid emulsion (IVLE) is being reported as a rescue measure for LA toxicity. This has been studied and proven in both animal models and in limited human trials with successful resuscitation outcomes. The lipid emulsion acts on the plasma and tissue and extracts the lipophilic anesthetic molecules, thereby reversing their inhibitory myocardial effects. Bolus doses of $1.2-2 \mathrm{ml} / \mathrm{kg}$ followed by continuous infusion of $0.25-0.5 \mathrm{ml} / \mathrm{kg} / \mathrm{min}$ are currently advocated for adequate efficacy. This drug needs to be used 
judiciously as optimal dosages have not been established and the risks of overdosage are not clearly understood.

\subsection{Reversal of Soft-Tissue Anesthesia}

The duration of soft-tissue anesthesia often exceeds that of pulpal or bony anesthesia. This is an important reason for the occurrence of undesirable events like accidental lip or tongue biting, difficulties in speaking, eating, or drinking liquids, etc. Various drugs have been studied to decrease the postoperative duration of anesthesia. Of the various drugs tried clinically, phentolamine is one drug, which has demonstrated appreciable clinical efficacy.

Phentolamine is a nonselective alpha-adrenergic antagonist that is reversible. Its main action is vasodilatation. It has been used effectively for controlling hypertensive emergencies, especially in pheochromocytomas. In dental practice, Phentolamine in the form of phentolamine mesylate injections has been used as a reversal agent against LA by reversing the action of vasoconstrictors in the LA solution and expedites the metabolism of the LA molecules. The recommended dose for phentolamine is the administration of $1.8 \mathrm{ml}$ of the solution containing $0.4 \mathrm{mg}$ of phentolamine mesylate immediately after treatment.

\subsection{Plain Local Anesthetic (Without Epinephrine)}

It is preferred for patients having comorbidities such as circulatory disorder to avoid complications and adverse systemic effects of vasoconstrictors [8]. Lip laceration is one of the common cases, which are attended to by a maxillofacial surgeon in the emergency department for suturing. Localized blanching caused by the use of local anesthetic with adrenalin at the lacerated wound causes difficulty in locating the exact demarcation between skin, white roll, and lip. Therefore, LA without epinephrine is preferred in such cases before suturing [9].

\subsection{Topical Local Anesthetic Agent}

The solution used for this purpose is 5\% Lignocaine, $10 \%$ Lignocaine, combination of $2.5 \%$ lignocaine and $2.5 \%$ prilocaine [10]. They are indicated in patients $[11,12]$

- For removal of maxillary and mandibular arch bars

- Gingival probing

- Deep Scaling

- Closure of facial lacerations in younger children

- Before LA injections in small patients

In suture and staple removal

\subsection{Surface Anesthesia}

The form of drug used to obtain this includes ointment, gel, viscous, cream, spray, etc. Topical application of these forms can produce anesthesia on the surface, particularly of the oral mucosa.

This is used often, before an actual injection for L.A, at the site of injection, in order to reduce the pain of the needle prick itself. It can also be used to obtund pain in situations where the oral mucosa is breached, as in an ulcer in the oral mucosa. The gel may also be used to anesthetize the surface mucosa, e.g., nasal, pharyngeal, etc., before a diagnostic endoscopy.

The concentration of a local anesthetic applied topically is typically greater than the same drug administered by injection. Drugs that are commonly employed in topical L.A formulations are Benzocaine and Lidocaine.

EMLA, which is a eutectic mixture of local anesthetic agents, lignocaine, $\&$ prilocaine in the ratio $1: 1$ by weight, has been found to be a very useful topical agent to be applied on the skin, before painful procedures like injection, venipuncture, etc. and is used extensively in children. This particular cream, which is oil-in-water emulsion, may also be used for surface anesthesia of the oral mucosa for purposes listed earlier.

\subsection{Methods of Local Anesthetic Administration}

There are major three different types of methods:

- Local infiltration

- Field block

- Nerve block

In local infiltration, deposition of the local anesthetic solution in the area of the surgery to anesthetize small terminal nerve endings. Field block involves the deposition of anesthetic solution near the large terminal nerve branches to prevent the passage of impulses from teeth to the central nervous system. In nerve block, local anesthesia is deposited away from the site of surgery, but close to the main nerve trunk.

Different techniques for mandibular nerve block anesthesia have been published, including the mental/incisive nerve block [13-15].

1. The standard (Halsted) technique

2. The standard indirect technique

3. Mental nerve (incisive nerve) block

- standard approach for mandibular anteriors and soft tissue

- anterior approach

- extraoral approach

4. Clarke-Holmes technique (1959) 
5. Vazirani technique (1960)

6. Akinosi technique (1977) closed-mouth technique

7. Wolfe technique (1992)

8. Sargenti technique (1966)

9. Gow-Gates technique (1973)

10. Ipsilateral open-mouth technique (2007)

11. Morishita (positive aspiration) technique (2007)

12. Extraoral submandibular approach

13. Lateral extraoral approach

14. Anterior extraoral approach. (1969)

Different maxillary nerve block techniques have been described.

1. Anterior-superior alveolar nerve and infraorbital nerve blocks,

- intraoral approach (bicuspid approach)

- Bisecting approach (central incisor)

- extraoral approach

- nasal approach (1969)

2. Posterior-superior alveolar nerve block (tuberosity block)

3. Middle-superior alveolar nerve block (buccal approach)

4. Middle and anterior-superior alveolar nerve block (palatal approach)

5. Sphenopalatine (incisive) nerve block

6. Greater palatine nerve and lesser palatine nerves block

7. Maxillary nerve blocks,

- High tuberosity approach

- Greater palatine canal approach

- nasal approach

- lateral extraoral approach

- suprazygomatic extraoral approach extraoral approach

- anterior-lateral extraoral approach.

\subsubsection{Percentage of Blood Vessel Penetration During IANB}

During IANB, the intravenous injection of local anesthetic is very common. Frangiskos $\mathrm{F}$ et al. [16], in their study, found positive aspiration (the tip of the needle is in the blood vessel) $20 \%$ times. The positive aspiration was more commonly seen in young patient's age ranging from 9 to 19 years. To avoid systemic complications while giving local anesthesia, aspiration is must in each and every case.

\subsubsection{Controversy in the Use of Bilateral IANB and Lingual Nerve Block [17]}

Has bilateral IAN and Lingual nerve block been given? Some surgeons recommend, while some do not, but there are no published data available regarding its contraindications. The common complications associated with its use are
- Collection of fluid in the oral cavity

- Injury to tongue

- Loss of control of tongue, which can lead to respiratory embarrassment

- Unpleasant effects of bilateral anesthesia [18].

Many authors advocated the use of sodium bicarbonate in addition to the lignocaine solution to reduce the duration of onset of anesthesia, and it is very effective in reducing pain during the injection. Sodium bicarbonate ions also nonspecifically reduce the safety margin for nerve conduction and it has a direct action on the binding of Local anesthetic to the sodium channel [19-21].

\subsection{Techniques}

\subsubsection{Inferior Alveolar Nerve Block (Also Known as Mandibular Nerve Block) [Along with Lingual \& Long Buccal Nerve Blocks]}

This is the single most important nerve block, whose technique needs to be mastered. With this, we can anesthetize the whole of the mandibular soft and hard tissues, including the cheek, and many procedures in this region can be carried out.

Secondly unlike in the maxilla, infiltration techniques do not provide adequate anesthesia to the hard tissue in the mandible, particularly the teeth. This is due to the dense cortical bone in the mandible, in contrast to the porous maxillary bone, where a paraperiosteal deposition of the solution can allow the solution to diffuse through the bone to the periapical region easily and cause anesthesia of the teeth and their supporting structures.

\subsubsection{Technique}

This description is for injection on the right side of the patient and for a right-handed operator. The surgeon is on the right side of the patient, in front of the patient. The patient is asked to open the mouth wide.

With the left hand, the operator palpates the posterior buccal sulcus, runs the index finger posteriorly to feel the external oblique ridge and the anterior border of the coronoid process. As the finger proceeds upwards, palpate the coronoid process up and down to determine the deepest point on its anterior border. This is the coronoid notch. [This is a very important landmark because this determines the vertical height at which the needle should be inserted, the reason being the Mandibular foramen on the medial aspect of the ramus where we want the needle to reach is in direct line with the coronoid notch] Fig. 5.1.

Once the coronoid notch is palpated with the pulp of the index finger, the finger is rotated such that the nail faces medially. At the same time, the finger retracts the soft tissue 


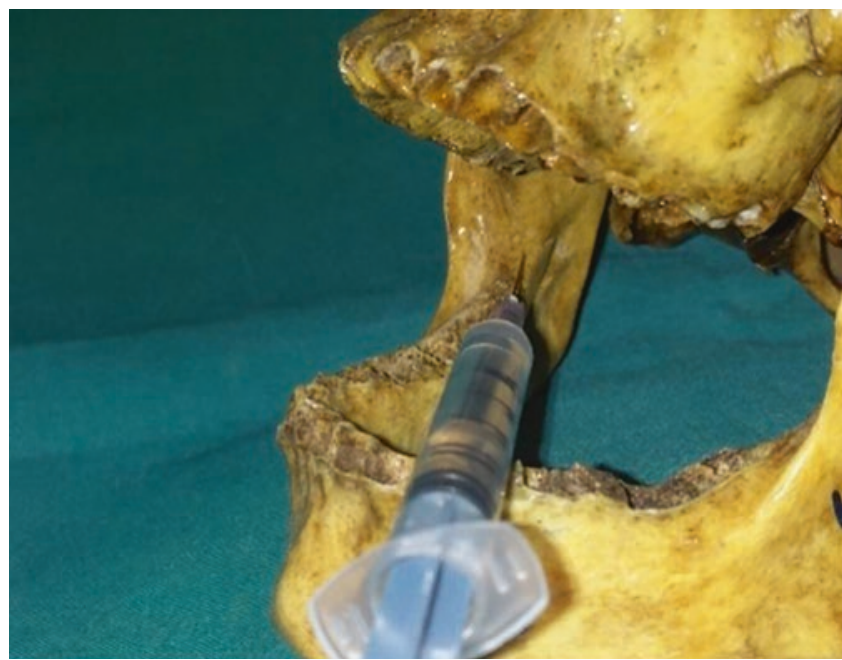

CAssociation of Oral and Maxillofacial Surgeons of India

Fig. 5.1 Dry mandible showing the position of needle and the coronoid notch

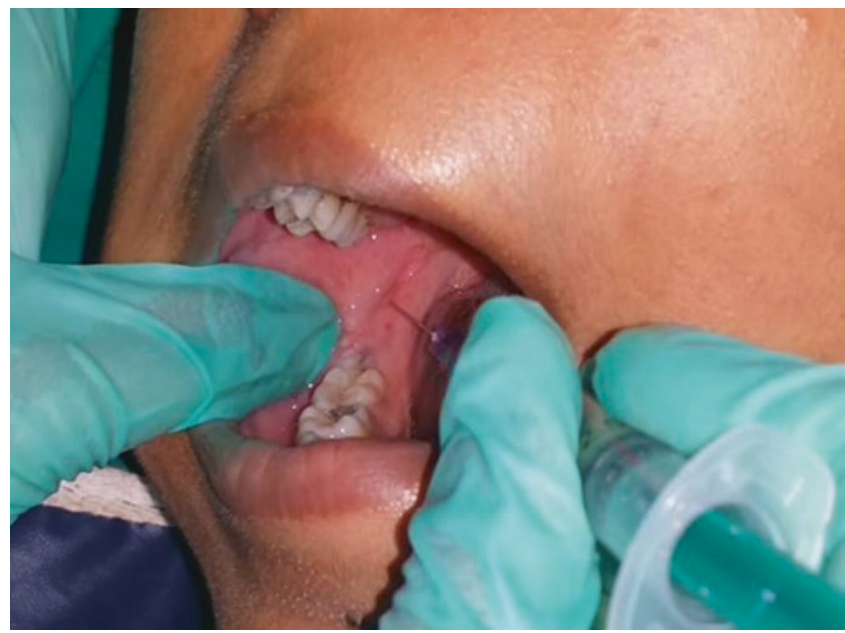

CAssociation of Oral and Maxillofacial Surgeons of India

Fig. 5.2 Picture showing needle insertion position from the soft tissue for IAN block

to reveal a depression called the pterygo mandibular depression, which is medial to the finger between the finger and the pterygo Mandibular raphe (Fig. 5.2).

Now the needle with solution in the syringe is taken in the right hand and is introduced into the mouth from the opposite side (i.e., left side) corner of the mouth/premolar area.

The syringe and needle are kept parallel to the Mandibular occlusal plane and are introduced into the pterygo temporal depression at the same height as the nail of the index finger (on the coronoid notch). The needle is advanced slowly in the soft tissue till the needle strikes the bone and resistance is felt. Now the needle is in the pterygo mandibular space bounded laterally by the medial surface of the ramus of the mandible and it is just above the lingula in the area of the opening of the mandibular foramen.
The syringe is aspirated and $1 \mathrm{ml}$ of the solution is deposited. This will anesthetize the inferior alveolar nerve as it enters the mandible. Now, the needle with the syringe is swung on to the corner of the mouth on the same side, i.e., right, and is slowly withdrawn after about half the length is inserted and $0.5-0.8 \mathrm{ml}$ of the solution is deposited here. This will take care of the lingual nerve, which is anteromedial to the inferior alveolar nerve.

Now the needle is withdrawn completely out of the soft tissue and is reinserted into the cheek, posterior to the last molar teeth at the level of the occlusal plane of the mandibular teeth for a short distance. After aspiration, the remaining $0.5 \mathrm{ml}$ of the solution is deposited. This anesthetizes the long buccal nerve [for the left-sided block, the surgeon is slightly behind the patient on the right side with the left hand coming around].

This classical Mandibular Nerve block of inferior alveolar nerve with lingual \& long buccal is done together if the mandibular molars and their adjoining soft tissues need to be anaesthetized. The reason being the pulp and the periodontium of these teeth are supplied by the inferior alveolar nerve. The lingual gingiva is supplied by the lingual nerve and the buccal gingiva by the long buccal nerve.

\subsubsection{Areas Anesthetized by This Block}

\section{Inferior Alveolar Nerve Block}

(a) All mandibular teeth and the bone surrounding them.

(b) The buccal gingiva in relation to the Mandibular anterior and premolar teeth.

(c) Lower lip on the same half up to the midline.

2. Lingual Nerve Block

(a) The lingual gingiva of the Mandibular teeth along with the lingual Mandibular mucosa.

(b) The Anterior 2/3rd of the tongue on the same side.

\section{Long buccal nerve Block}

(a) The cheek mucosa.

(b) Buccal gingiva and mandibular mucosa in relation to the molar teeth.

\subsubsection{Signs and Symptoms of Anesthesia}

It usually takes about 3-5 min before adequate depth of anesthesia is obtained after any injection. In other words, although symptoms of anesthesia may be felt almost instantly after the injection, for the patient to feel no pain during the procedure a wait of at least $5 \mathrm{~min}$ is needed.

It has been conventional to confirm the anesthesia obtained with two parameters:

1. Subjective symptoms of anesthesia as experienced by the patient.

2. Objective signs elicited by the surgeon. 
Subjective symptoms may or may not be present with certain nerve blocks, e.g., nasopalatine block. However with the classical inferior alveolar/mental nerve block, a tingling and numbness on one half of the lip (same side) will be felt. There will be an area of sharp demarcation between the numb side of the lip and the normal side at the midline. The tingling or numbness will start instantly to become heavy in about 3-5 min. Similar sensation of numbness will be felt on the same side of the tongue particularly the tip as a result of the lingual nerve block. There may be no symptoms of numbness felt by the patients in the other anaesthetized areas, e.g., the gingiva, teeth, or the cheek.

The objective sign as elicited by the surgeon is more reliable and may be the only means of ascertaining anesthesia in the absence of subjective symptoms. The objective sign of anesthesia is lack of pain in the area anesthetized when stimulus is applied with a blunt instrument, e.g., the end of a periosteal elevator. [It should be noted from the earlier discussion that the patient might feel the pressure of the instrument and an apprehensive patient might occasionally interpret this as pain.]

In checking for anesthesia of the inferior alveolar nerve, the blunt instrument must be applied on the buccal gingiva anterior to the mental foramen, because the lack of sensation in the posterior buccal soft tissue indicates a successful long buccal nerve and not inferior alveolar nerve block. The same blunt instrument must be applied in the gingival sulcus on the lingual side of the tooth to be extracted for lingual nerve anesthesia. The same can be done to check the buccal nerve anesthesia.

\subsubsection{Complications (Table 5.6)}

These were discussed very briefly as local complications of L.A in the earlier section. Specific complications after an Inferior Alveolar Nerve block include:

1. Failure to obtain anesthesia

2. Hematoma formation

3. Transient facial nerve palsy/weakness

4. Trismus

5. Breakage of the needle.

Table 5.6 Complications with local anesthetics

\begin{tabular}{l|l}
\hline Local & Systemic \\
\hline Needle breakage & Syncope \\
Paresthesia & Adverse drug reactions \\
Facial nerve paralysis & Overdose drug reactions \\
Trismus & Psychogenic reactions \\
Soft-tissue injury & \\
Hematoma & \\
Pain on injection & \\
Burning on injection & \\
Infection & \\
Edema & \\
Sloughing postanesthetic intraoral lesion &
\end{tabular}

\subsubsection{Failure to Obtain Anesthesia}

It is the most common problem and usually due to the wrong technique. Repeating the block employing the right technique is usually the solution. However, this might be encountered in two other situations.

1. Failure to anesthetize the myolohyoid branch, which might occasionally innervate the site of the procedure.

2. Also as already mentioned, in an apprehensive patient, the symptoms of pressure may be interpreted as pain. In this situation, anxiety reduction techniques may be needed or alternately some other form of anesthesia, e.g., conscious sedation or General Anesthesia may have to be employed. The subjective symptom of numbness in the lower lip (same side) and tip of the tongue will be the distinguishing feature between a faulty technique and an apprehensive patient. In the former, it will be absent, and in the latter very much present.

\subsubsection{Hematoma Formation}

This may occur within the pterygo mandibular space as a result of bleeding induced by the needle prick. It may be a rare problem. The patient might have pain, swelling, \& difficulty in opening the mouth. The treatment is symptomatic and possibly prophylactic antibiotic cover. It will resolve spontaneously.

\subsubsection{Transient Facial Nerve Palsy}

May occasionally occur as a result of a faulty technique where the needle is inserted farther posteriorly into the substance of the parotid gland (in this situation, the needle would have failed to encounter bony resistance) and paralyzes the facial nerve.

The patient will have typical signs of ipsilateral facial nerve palsy/weakness, which includes difficulty in closing the eye, absence of wrinkles on the forehead, and drooping of the corner of the mouth ipsilaterally with a possible asymmetry. This effect will be transient, till such time the local anesthetic effect persists (about $1-1 \frac{1}{2} \mathrm{~h}$ ) and the patient needs to be reassured.

\subsubsection{Trismus}

Is a relatively more common complication and will be seen usually postoperatively. It could be due to a variety of causes, including:

1. Muscle spasm due to injury

2. Infection

3. Necrosis of tissue due to contact with contaminants, etc.

Most of the time it resolves spontaneously. But on occasion, this will require anti-inflammatory analgesics, muscle relaxants, and vigorous physiotherapy to overcome the problem. Wherever an infection is suspected, a suitable antibiotic cover may also be needed. 


\subsubsection{Accidental Breakage of the Needle}

Occurring within the tissues of the pterygo mandibular space, this is a very rare complication today where we use disposable needles for one use only. But when this happens, a radiographic guided exploration and removal of the broken piece may be needed. Gerbino G et al. [22] advocated use of brain $\mathrm{LAB}$ vector vision neuronavigation system for the retrieval of broken needle. This Intraoperative navigation system is very helpful in locating the broken needle fragment.

\subsection{Vazirani-Akinosi (VA) Versus Inferior Alveolar Nerve Block}

The closed mouth VA technique to anesthetize the IAN, lingual, and long buccal nerve simultaneously was described in 1977 [23]. VA is used only secondarily to conventional IAN block.

\subsubsection{Indications for VA [24]}

1. In patients with restricted mouth opening

2. In cases of failure of IAN blocks

3. Difficult-to-locate landmarks for IAN block

The percentage of Positive aspiration is much higher with IAN block in comparison to VA. This is because of the close proximity of the inferior alveolar artery, which enters the mandibular foramen just behind the nerve [25]. To avoid frequent aspiration, many surgeons prefer VA technique in normal patients also.

\subsubsection{Akinosi-Vazirani Technique (Closed- Mouth Technique)}

A 25-gauge long needle is used. The operator is in front of the patient on the right side (right-handed operator) for both sides on the patient.

With the left index finger or thumb, the coronoid notch is palpated and the soft tissues on the medial aspect of the ramus are pushed laterally. The needle is held parallel to the maxillary occlusal plane on the same side of the injection and is inserted adjacent to the maxillary third molar into the soft tissue overlying the medial border of the ramus, just adjacent to the maxillary tuberosity. This is now advanced posteriorly \& slightly laterally. The bevel of the needle is away from the mandibular ramus and in an average-sized adult the needle is inserted about $25 \mathrm{~mm}$ into the tissue. At this point, the tip of the needle will be in the middle of the pterygo mandibular space close to the branches of the mandibular nerve. After aspiration, the LA solution is injected.

The areas anesthetized, signs and symptoms of anesthesia are similar to the open-mouth technique of mandibular nerve block.
Another viable alternative to the VA block is the technique of Gow-Gates described in 1973. In the Gow-Gates technique, anesthesia is administered more proximally, at the neck of the condyle and relies on extraoral landmark [26].

\subsubsection{Technique}

A 25-gauge long needle is used. The operator stands in front of the patient. It is very essential for the patient to extend his neck \& open the mouth as wide as possible. Here the needle is inserted into the mucosa medial to the mandibular ramus on a line parallel to a line drawn from the intertragic notch to the corner of the mouth - just distal to the maxillary second molar. The needle is inserted from the corner of the mouth on the opposite side. The height of insertion is just at the level of the mesiolingual cusp of the maxillary second molar. Slowly advance the needle till the bone is contacted. (The needle here is in contact with the neck of the condyle. The position the patient is asked to assume, i.e., extend neck \& open mouth wide, is to facilitate a more frontal position of the condyle closer to the mandibular nerve trunk). The average depth of insertion is about $25 \mathrm{~mm}$. Aspirate \& inject $2 \mathrm{ml}$ of the solution slowly. Unlike with the classical method, injection is at one site only in this technique. This anesthetizes the inferior alveolar, lingual, long buccal branches of the mandibular here with similar effect as the classical block (Fig. 5.3a, b).

\subsection{Mental/Incisive Nerve Block}

These are two very similar blocks except that in a mental block the solution is deposited around the mental nerve as it exits the mandible at the mental foramen, whereas for an incisive nerve block, the solution is injected into the mandible through the mental foramen. This blocks the incisive nerve, which is the continuation of the inferior alveolar nerve anteriorly, up to the midline.

\subsubsection{Technique}

This may be carried out with the operator standing in front of the patient (can also be done easily with the operator standing behind).

With the left-hand thumb or index finger, palpate the mucobuccal fold on the mandible starting in the molar region moving anteriorly when depression will be felt. This is usually in relation to the apex of the premolar teeth where the mental foramen is present. The needle is now directed vertically to be inserted into this area with the bevel facing the bone. With the mental nerve block, the solution is deposited in the soft tissues, whereas for the incisive the needle is inserted into the foramen for a short distance before injection. 

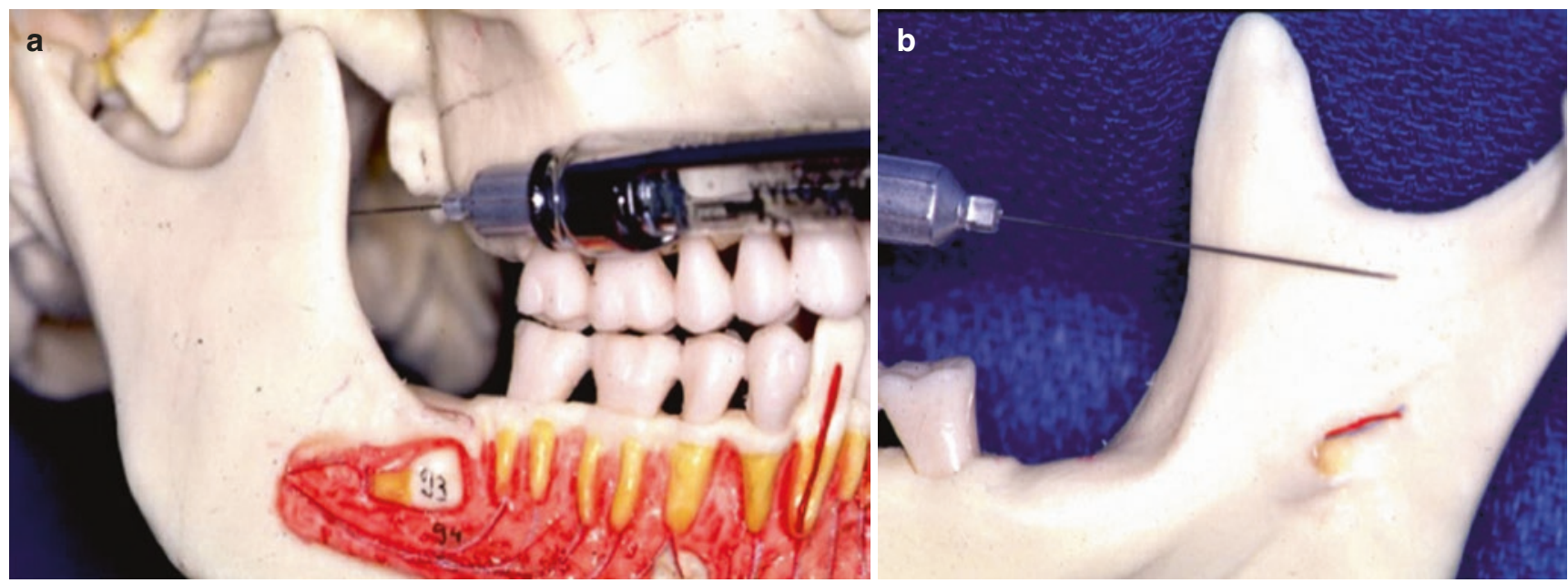

CAssociation of Oral and Maxillofacial Surgeons of India

Fig. 5.3 (a, b) Position of needle from medial and lateral aspect in case of closed-mouth technique

\subsubsection{Areas Anesthetized}

Mental Nerve Block: Buccal mucosa and gingiva in the mandible anterior to the premolar area, lower lip mucosa, and skin on the same side.

Incisive Nerve Block: In addition to the aforementioned structures, mandibular teeth anterior to the mental foramen, i.e., incisors, canine, and the premolars (which are anterior to the mental foramen).

\subsubsection{Signs and Symptoms}

Subjective: Tingling and numbness in the lower lip on the same side for both blocks as it is for the inferior alveolar block.

Objective: Lack of pain on probing with a blunt instrument over the buccal gingival/mucosa in the anterior Mandibular region.

Complications: Hematoma formation: If there is bleeding submucosally or subcutaneously, pressure application to stem the flow is all that is needed, with reassurance to the patient that it will resolve spontaneously in a short period of days.

\subsection{Nerve Blocks in the Maxilla}

As already mentioned, in maxilla buccal \& palatal infiltration techniques are often followed because they are effective, particularly if the surgical area is limited, e.g., extraction of a single tooth. However nerve blocks are useful at times, particularly when anesthesia of a larger area is sought.

\subsubsection{Posterior Superior Alveolar Nerve Block Technique}

The position of the operator is on the front of the patient for both sides, on the right side, for a right-handed operator.

Palpate the maxillary mucobuccal fold after asking the patient to open mouth partially and retracting the buccal soft tissue with the index finger of the left hand. Insert the needle (25/27 gauge20-mm length) into the height of the mucobuccal fold opposite the upper second (second) molar tooth. Advance the needle in inward, upward, backward direction with the needle at $45^{\circ}$ angle to the maxillary plane for about $10-15 \mathrm{~mm}$. The tip of the needle will now be close to the entry of the posterior superior alveolar nerve into the maxilla on its posterior surface. Inject $1-1.5 \mathrm{ml}$ of the solution after aspiration (Fig. 5.4).

\subsubsection{Areas Anesthetized}

1. Buccal alveolar mucosa and gingiva in relation to the maxillary molar teeth.

2. All the three maxillary molar teeth except the mesiobuccal root of the first molar in some instances. (This may be supplied by the middle superior alveolar nerve occasionally. In this case, to anesthetize the first molar tooth completely, a buccal infiltration has to be given in addition to the posterior superior alveolar nerve block if employed.)

Hence, this is a nerve block, which may be used if multiple extractions of molar teeth have to be done in the maxilla or any other procedure in this area.

\subsubsection{Signs and Symptoms}

Subjective: The patient usually will not feel any tingling or numbness in this case. 
Objective: Lack of pain on probing with the blunt instrument as with any other local anesthetic injection.

Complications: Most common problem is a swiftly developing hematoma particularly if the needle goes too far distally into the area of the pterygoid venous plexus.

As in earlier instances, pressure needs to be applied in this case, on the face above the area where the swelling is developing. The sudden swelling can be alarming but is of little consequence once the application of pressure stops flows.

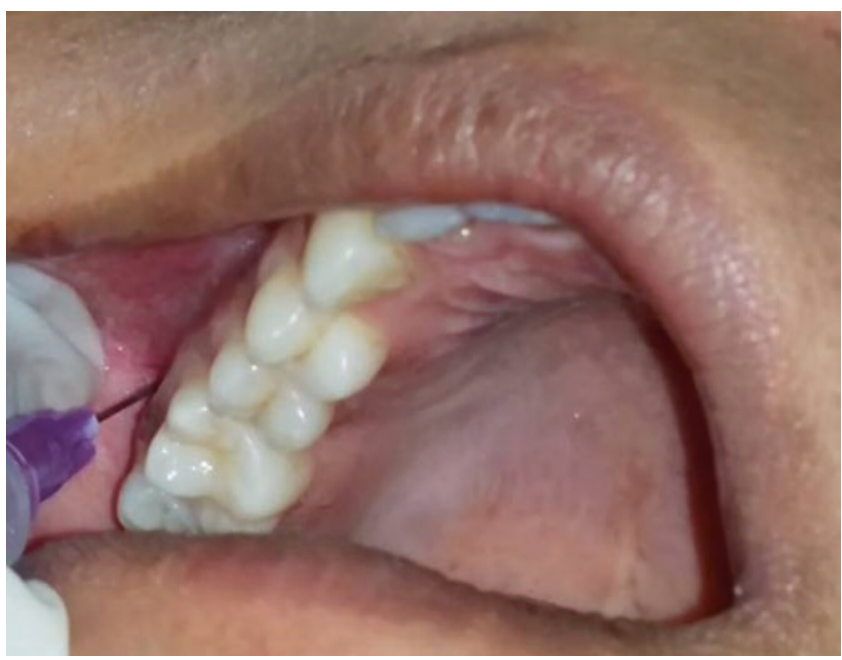

CAssociation of Oral and Maxillofacial Surgeons of India

Fig. 5.4 Needle insertion position in posterior superior alveolar nerve block
Once again, reassurance to the patient is needed. Prophylactic antibiotics to prevent secondary infection of the hematoma may be considered.

\subsubsection{Infraorbital Nerve Block [Also Anterior and Middle Superior Nerve Blocks]}

\subsubsection{Technique}

The operator (right handed) is on the right side of the patient for both sides, i.e., left $\&$ right.

With the left index finger, the infraorbital rim on the face is palpated. A notch is felt on the medial third of this region, the finger is now slid down to feel for depression below this notch on the anterior surface of the maxilla. This is the position of the infraorbital foramen. With the left index finger over the infraorbital foramen, the cheek is retracted with the thumb and a 25-gauge needle is inserted intraorally into the height of the mucobuccal fold opposite the first premolar with the bevel of the needle directed toward the bone and the needle being parallel to the long axis of the tooth. The needle is advanced until gentle bone contact is made, and this will be the upper rim of the infraorbital foramen.

Aspirate and inject about $1-1.5 \mathrm{ml}$ of the solution. As the solution is deposited, firm pressure is applied over the infraorbital foramen by the left-hand index finger so as to facilitate entry of the solution into the infraorbital canal through the foramen (Fig. 5.5a, b).
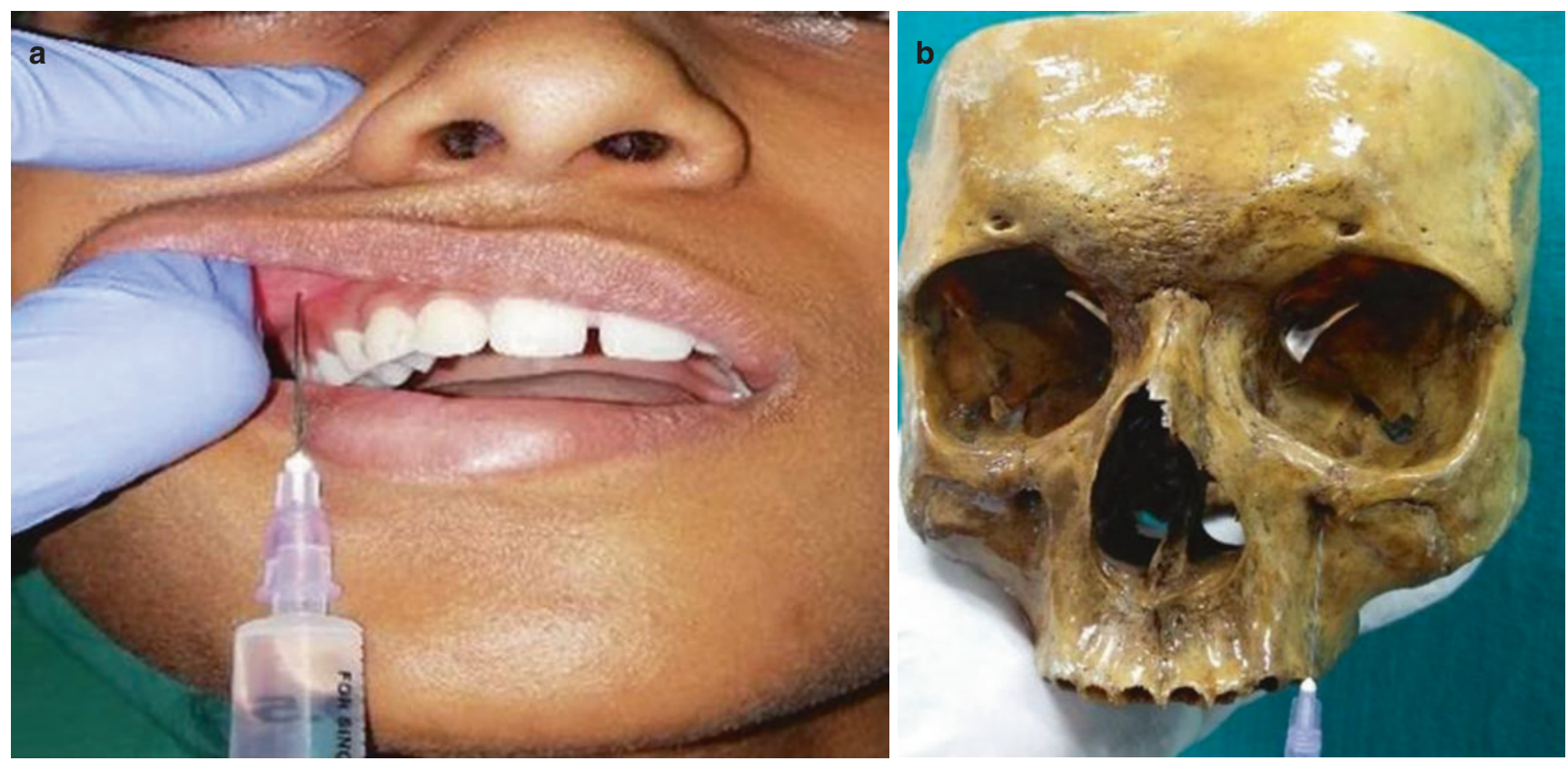

CAssociation of Oral and Maxillofacial Surgeons of India

Fig. 5.5 (a, b) Position of needle insertion and target point in dry skull in Infraorbital nerve block 


\subsubsection{Areas Anesthetized}

1. The lower eyelid, lateral side of the nose, and the upper lip on the same side (This is due to blockade of the terminal branches of the infraorbital nerve after it exits the foramen and will happen irrespective of whether the solution has entered into the foramen)

2. The buccal gingiva \& mucosa, as well as the upper anterior and premolar teeth on the same side as well as the mesiobuccal root of the first molar if it is supplied by the middle superior alveolar nerve. (For this to happen, the anesthetic solution injected should diffuse into the infraorbital canal in the floor of the orbit from where the branches, anterior, \& middle superior alveolar nerve are given off.)

\subsubsection{Signs and Symptoms of Anesthesia}

Subjective: Tingling \& numbness in the areas supplied by the terminal branches of the infraorbital nerve, i.e., the lower eyelid, lateral side of the nose, and the upper lip on the same side. (This symptom does not necessarily mean that the anterior \& middle superior alveolar nerves have been anesthetized. This can be confirmed only objectively.)

Objective: Like always, lack of pain on probing with a blunt instrument in the area anesthetized.

Complication: Are few. Rarely a hematoma may develop.

\subsubsection{Palatal Anesthesia}

Injection into the palatal tissues, whether an infiltration or a nerve block, is the most painful. The reason is the palatal mucoperiostem is tightly adherent to the bone and there is no easy space for the solution to flow. This also makes the process of injection difficult as often there is backflow due to the resistance offered.

Most often, particularly when a single tooth is involved, infiltration anesthesia is preferred in the palate. However, two nerve blocks are often used particularly when a larger area is involved

1. Greater palatine nerve block

2. Nasopalatine or Anterior Palatine Nerve block.

\subsubsection{Greater Palatine Nerve Block}

Technique: The greater palatine foramen in the adult is usually present on the palatal side of the second molar tooth at the junction of the alveolus and the horizontal palatine bone. (This may be palpated as a depression in this area but need not be done for the purpose of the nerve block.)

A 25/27-gauge short needle is inserted from the opposite side with the operator standing in front (for both sides of the patient) into the area palatal to the second molar at the junction of the alveolus \& the palatine bone (Fig. 5.6a, b). A little solution is deposited $(0.1-0.2 \mathrm{ml})$ at the point of entry and
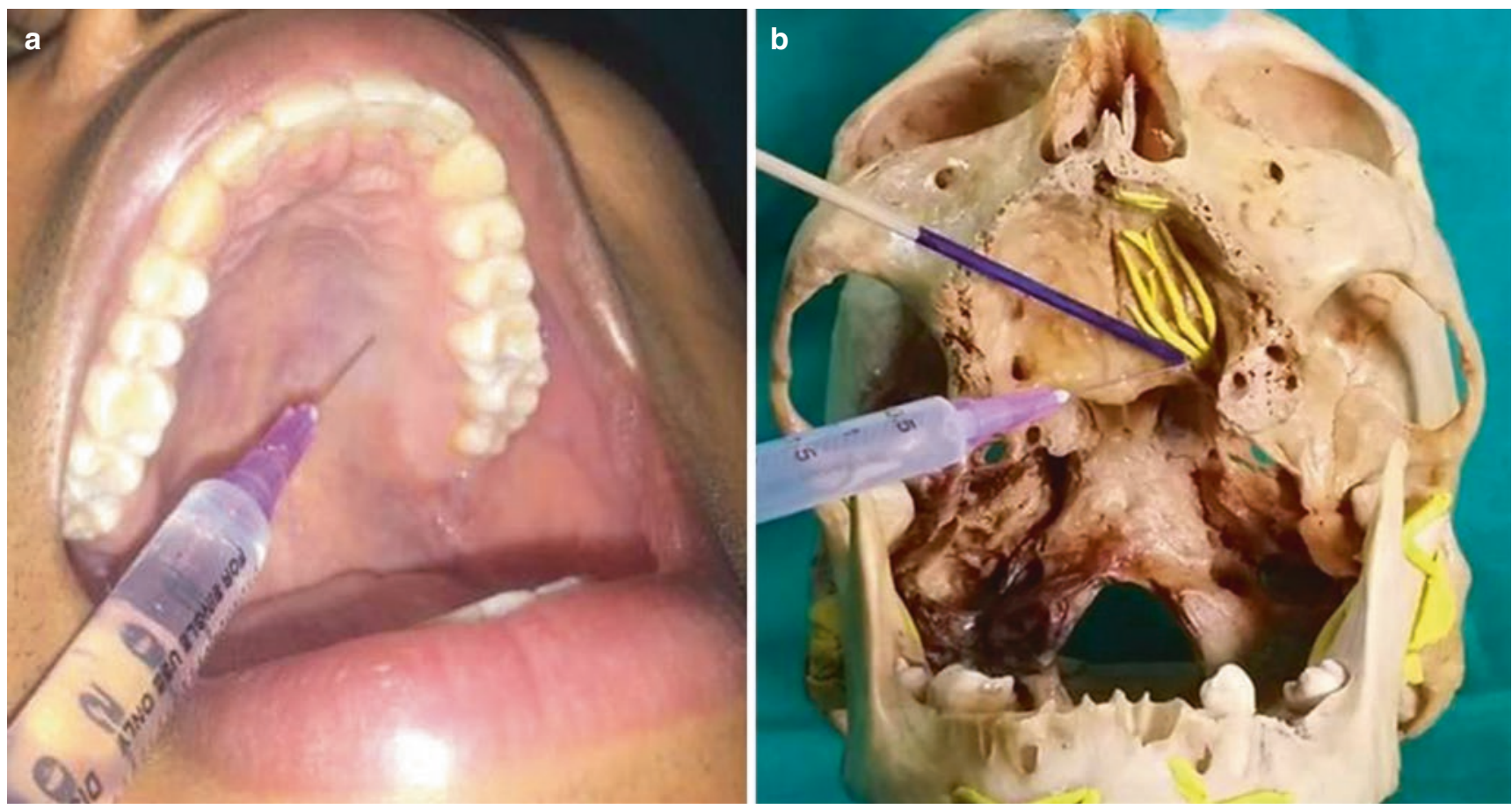

CAssociation of Oral and Maxillofacial Surgeons of India

Fig. 5.6 (a, b) Intraoral and in dry skull showing insertion of needle in greater palatine nerve block 
the needle is advanced into the foramen for a variable distance $(0.5-0.7 \mathrm{~cm})$ and the rest, about $0.8 \mathrm{ml}$ is deposited. As usual, always aspirate before depositing any solution.

Areas Anesthetized: The palatal gingiva of the maxillary teeth till the second premolar on the same side as well as the palatal mucosa \& bone on the same side till the premolar region.

\section{Signs and Symptoms of Anesthesia}

Subjective: May not always be there. However, numbness in the posterior hard palate mucosa may be present.

Objective: Confirmation of anesthesia is always by lack of pain in the area and tested by probing with a blunt instrument.

\subsubsection{Nasopalatine Nerve Block}

Technique: Operator in front with the patient mouth wide open, a 25/27 gauge needle is inserted into the palate just lateral to the incisive papilla. A small amount $0.1-0.2 \mathrm{ml}$ of the solution is injected after aspiration. Now the needle is advanced further into the incisive foramen for a distance of about $0.5-0.75 \mathrm{~cm}$ and $1 \mathrm{ml}$ of the solution is deposited as always after aspiration.

Areas Anesthetized: Probably the only nerve block, which anesthetizes bilaterally symmetrical areas and hence there is no separate right- \& left-sided blocks. The palatal gingiva of the anterior teeth up to the first premolar on either side as well as the palatal mucosa and bone in the same anterior region.

\section{Signs and Symptoms}

Subjective: May be variable if present there is numbness of the anterior palate.

Objective: lack of pain in the anesthetized area on blunt probing.

The various nerve blocks discussed so far are the commonly used techniques. Usually this set of techniques is sufficient for all requirements of local anesthesia in the oral cavity. There are a number of alternative techniques, intraoral and extraoral, which are described in literature and may be popular in some parts of the world. However, a couple of them will be discussed here because they may have a specific indication or may be a popular technique.

\subsection{Regional Blocks in Oral and Maxillofacial Surgery}

Regional blocks are fast becoming popular in providing not only local anesthetic support for performing surgical procedures of the head and neck, but also as a method for perioperative pain control in the form of pre-emptive anesthetic techniques.
This section focuses on a few regional blocks, which can be added to the armamentarium of today's maxillofacial surgeon.

1. Maxillary nerve block

2. Mandibular nerve block

3. Greater auricular nerve block

4. Glossopharyngeal nerve block \&

5. Sphenopalatine ganglion nerve block

\subsubsection{Maxillary Nerve Block}

There are numerous techniques for achieving total maxillary nerve anesthesia for dental and maxillofacial surgical procedures. These may be divided into intraoral and extraoral methods [27].

The intraoral techniques include:

1. The "Greater Palatine Canal" Approach where a 25 -gauge needle is passed and manipulated through the greater palatine canal to reach the maxillary nerve trunk at the pterygopalatine fissure (PTM fissure) and

2. The "High Tuberosity" Block Technique where the maxillary nerve is anesthetized as it traverses the pterygomaxillary fissure. The technique involves the insertion of a 1.5-in. 25-gauge needle through the depth of the mucobuccal fold lateral to the maxillary tuberosity in a fashion similar to the posterior superior alveolar nerve block. The depth of penetration is about $30 \mathrm{~mm}$ and the target area is the pterygomaxillary (ptm) fissure posterolateral to the maxillary tuberosity.

The extraoral technique [28, 29]:

It involves a subzygomatic, technique. The clinical landmarks include the area below the zygomatic arch anterior to the articular eminence. This corresponds to the region above the midpoint of the sigmoid notch of the mandible. A 25-gauge 90-mm-long spinal needle is preferred for this method; the needle is inserted to a depth of about $45 \mathrm{~mm}$ till it contacts the lateral side of the lateral pterygoid plate. The needle is then withdrawn half-way and then angulated $15^{\circ}$ in the forward and upward directions, which lead it to the region of the superior aspect of the ptm fissure, which corresponds to the exit of the maxillary nerve from the foramen rotundum across the ptm fissure. After negative aspiration, a volume of $2 \mathrm{ml}$ is injected into the space, and the needle is withdrawn (Fig. 5.7).

\subsubsection{Mandibular Nerve Block}

The extraoral technique for the mandibular nerve block is very similar to the maxillary nerve block [30].

Technique-The surface landmarks and point of penetration for the block are the same and so is the armamentarium. The needle after penetrating the skin is advanced to 


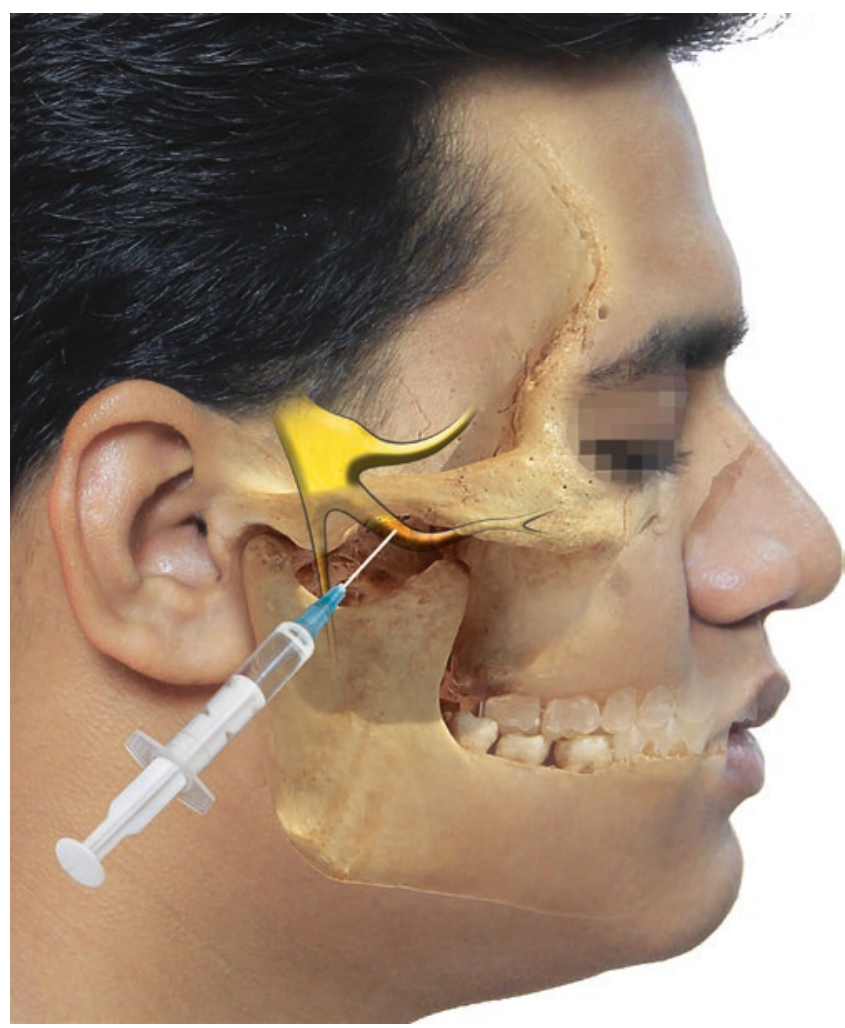

CAssociation of Oral and Maxillofacial Surgeons of India

Fig. 5.7 Representing pathway of needle in extraoral maxillary nerve block

contact the lateral pterygoid plate as described earlier, following which the needle is withdrawn half way and turned posteriorly by $15^{\circ}$ to the same depth of $45 \mathrm{~mm}$. This area corresponds to the region just caudal to the foramen ovale through which the mandibular nerve trunk exits the skull base. After negative aspiration, a volume of $2.5-3 \mathrm{ml}$ is injected to anesthetize the mandibular nerve.

The extraoral mandibular nerve block with suprazygomatic access can be safely and efficiently used with this unique approach for the mandibular nerve block to get relief in pain and Trismus. After local infiltration, an 18-gauge insulated and stimulating cannula is inserted into the retrozygomatic space just above the zygomatic arch and directed to the angle of mandible with medial and posterior inclination (Fig. 5.8) [31].

\subsubsection{Greater Auricular Nerve Block}

This nerve block is performed as an extraoral technique and provides good surface anesthesia to the periauricular skin and skin over the angle of the mandible [32].

Technique-The landmarks used for this technique include the cricoid cartilage and the posterior border of the sternocleidomastoid muscle. With the patient supine or semisupine, a line is drawn from the cricoid cartilage to

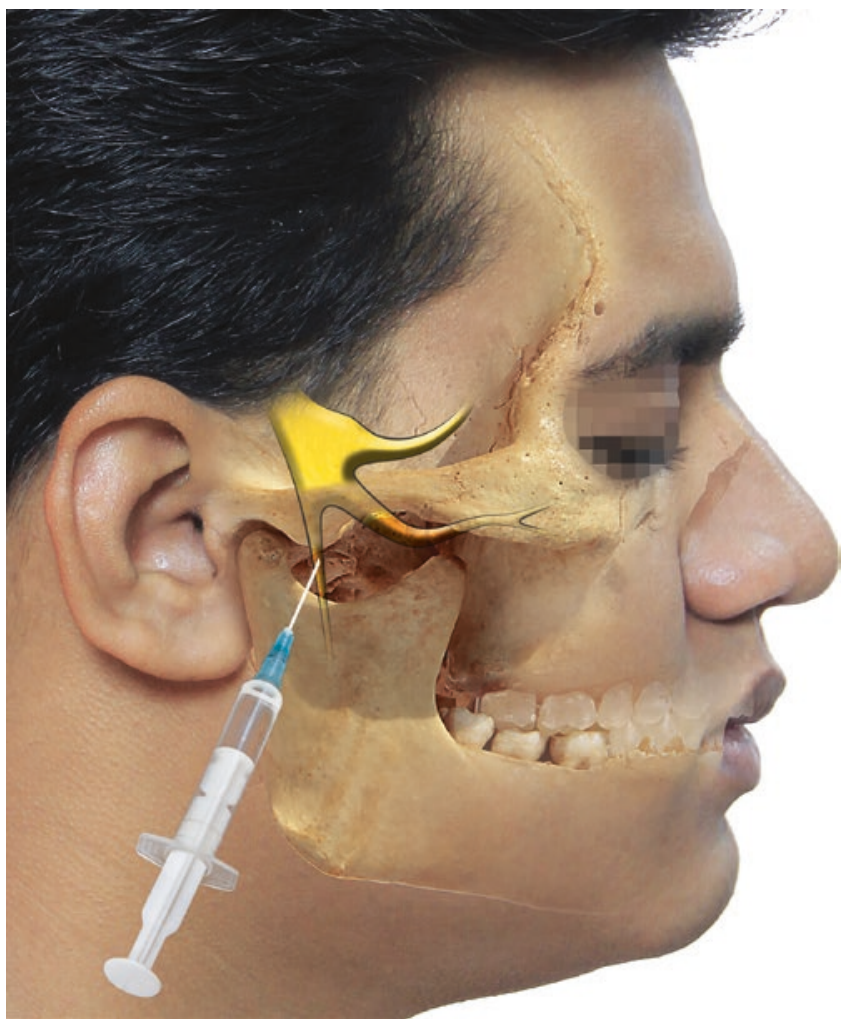

CAssociation of Oral and Maxillofacial Surgeons of India

Fig. 5.8 Showing position of needle insertion in extraoral mandibular nerve block

intersect the posterior border of the sternomastoid muscle. This corresponds to the area where the superficial branches of the cervical plexus emerge from under the sternomastoid muscle, wrapping around the posterior border. A small subcutaneous injection of local anesthetic solution (around $2 \mathrm{ml}$ ) will anesthetize the greater auricular nerve and its area of distribution (Fig. 5.9).

\subsubsection{Glossopharyngeal Nerve Block}

The utility of the glossopharyngeal block has been studied in indications such as:

1. Excessive gag reflex during oral procedures

2. Excellent adjuvant for oropharyngeal anesthesia during awake endotracheal intubations (blind nasal or fibro-optic)

3. Management of pain due to glossopharyngeal neuralgias and atypical facial pain secondary to Eagle's syndrome [33-35]. The block can be administered both via an intraoral and an extraoral method. The intraoral technique is a relatively easy and simple technique to administer producing good outcomes.

Technique-A 25-gauge, 1 inch needle is chosen. The landmark for penetration is the base of the anterior tonsillar 


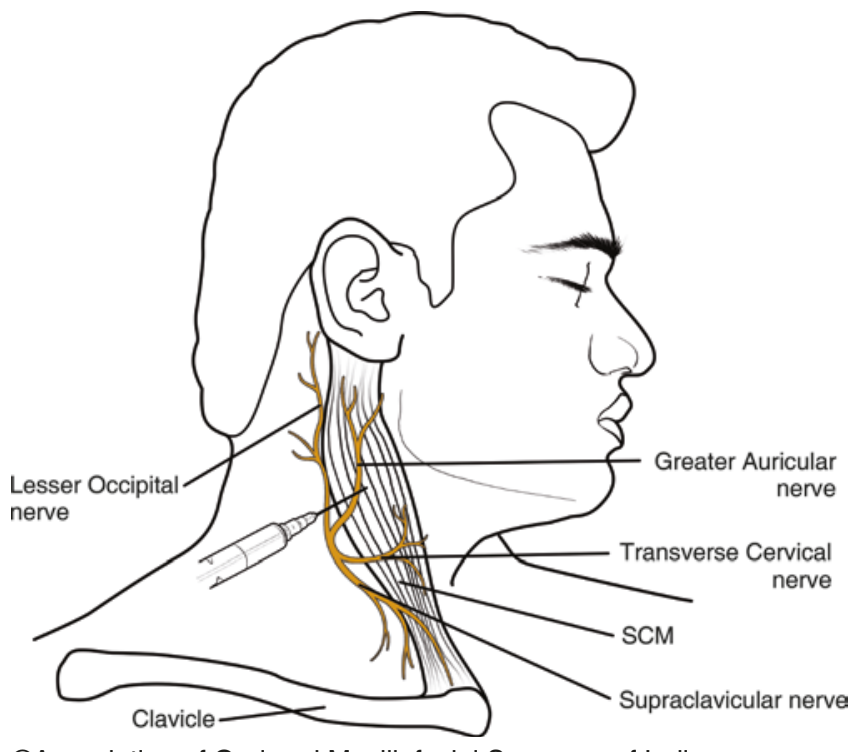

CAssociation of Oral and Maxillofacial Surgeons of India

Fig. 5.9 Showing position of needle for greater auricular nerve block

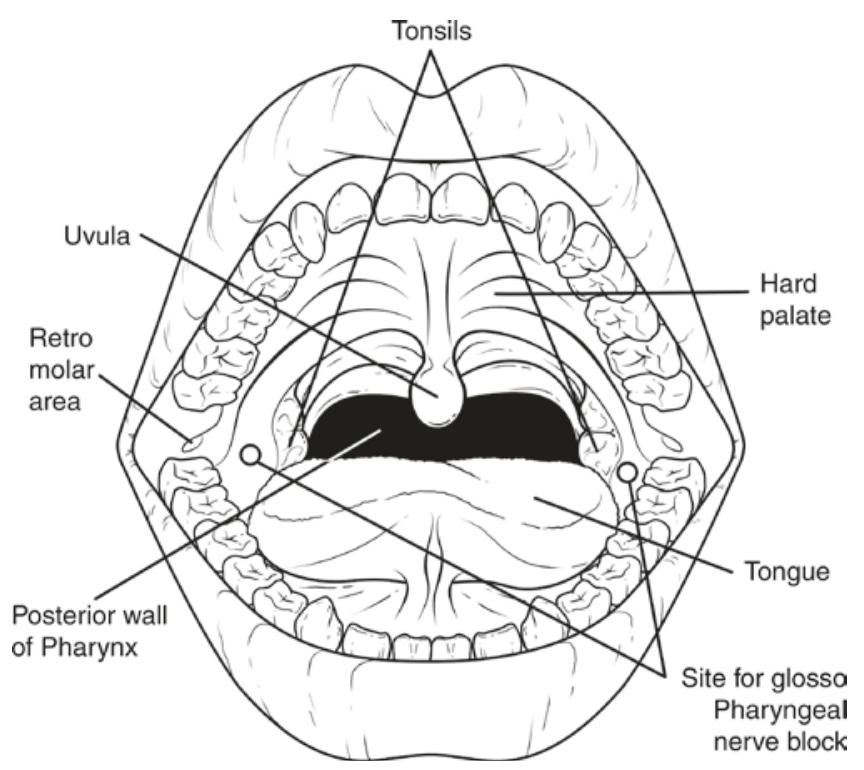

CAssociation of Oral and Maxillofacial Surgeons of India

Fig. 5.10 Target area for glossopharyngeal nerve block

pillar lateral to the base of the tongue. The syringe is positioned with the barrel near the maxillary premolar of the contralateral side with the needle facing the base of the anterior tonsillar pillar. The tongue is retracted medially to provide good visualization of the involved site. The needle is then made to pierce the mucosa and advance by $5 \mathrm{~mm}$. This corresponds to the target site for the glossopharyngeal nerve in the submucosal space. After judicious aspiration, if found negative, a volume of $3 \mathrm{ml}$ of anesthetic solution (2\% lignocaine) is administered to block the nerve trunk (Fig. 5.10).

\subsubsection{Sphenopalatine Ganglion Block}

Indications for sphenopalatine ganglion block include:

1. Management of cluster headaches and migraine

2. Treatment for atypical facial pain

3. Palliative pain control for patients with maxillary malignancies and

4. Pre-Emptive nerve blockade for perioperative pain control in surgical procedures of the maxilla and palate $[36,37]$

Technique-There are numerous techniques for the administration of sphenopalatine block, but the most commonly followed methods are the greater palatine approach and the transmucosal approach in the posterior aspect of the middle meatus. The greater palatine approach is the same as the maxillary nerve block via the greater palatine canal, which simultaneously blocks the sphenopalatine ganglion as well. The transmucosal method, which is most commonly followed, maybe done blind or using endoscopic guidance. A cotton pledget on a long application stick is dipped in anesthetic solution or gel and is advanced transnasally to the posterior aspect of the middle turbinate to reach the end of the middle meatus. This corresponds to the level of the sphenopalatine ganglion, which is a very superficial structure. The local anesthetic gel is then deposited, which produces anesthesia through transmucosal perfusion. Another recent technique involves the submucosal injection of the anesthetic solution into the posterior aspect of the middle meatus for achieving the block (Fig. 5.11) [37].

\subsection{Recent Advances in Local Anesthesia}

Research is ongoing to find newer modalities of pain management. In order to administer local anesthesia with less pain and adverse effects, newer technologies have been developed. Some of them are:

\subsubsection{Vibrotactile Devices}

This device is based on the Gate Control theory, which proposes that pain during injection can be decreased by simultaneous stimulation of nerve fibers by vibration.

\subsubsection{Vibraject [38]}

An attachment, which is battery operated, is snapped on to the barrel to deliver strong vibrations, which is felt by the patient and therefore reducing the perception of pain.

\subsubsection{Dental Vibe [39]}

It is a handheld device, which delivers pulsed percussive oscillations to the site of injection, thereby closing the pain 
Fig. 5.11 Showing technique of sphenopalatine ganglion block
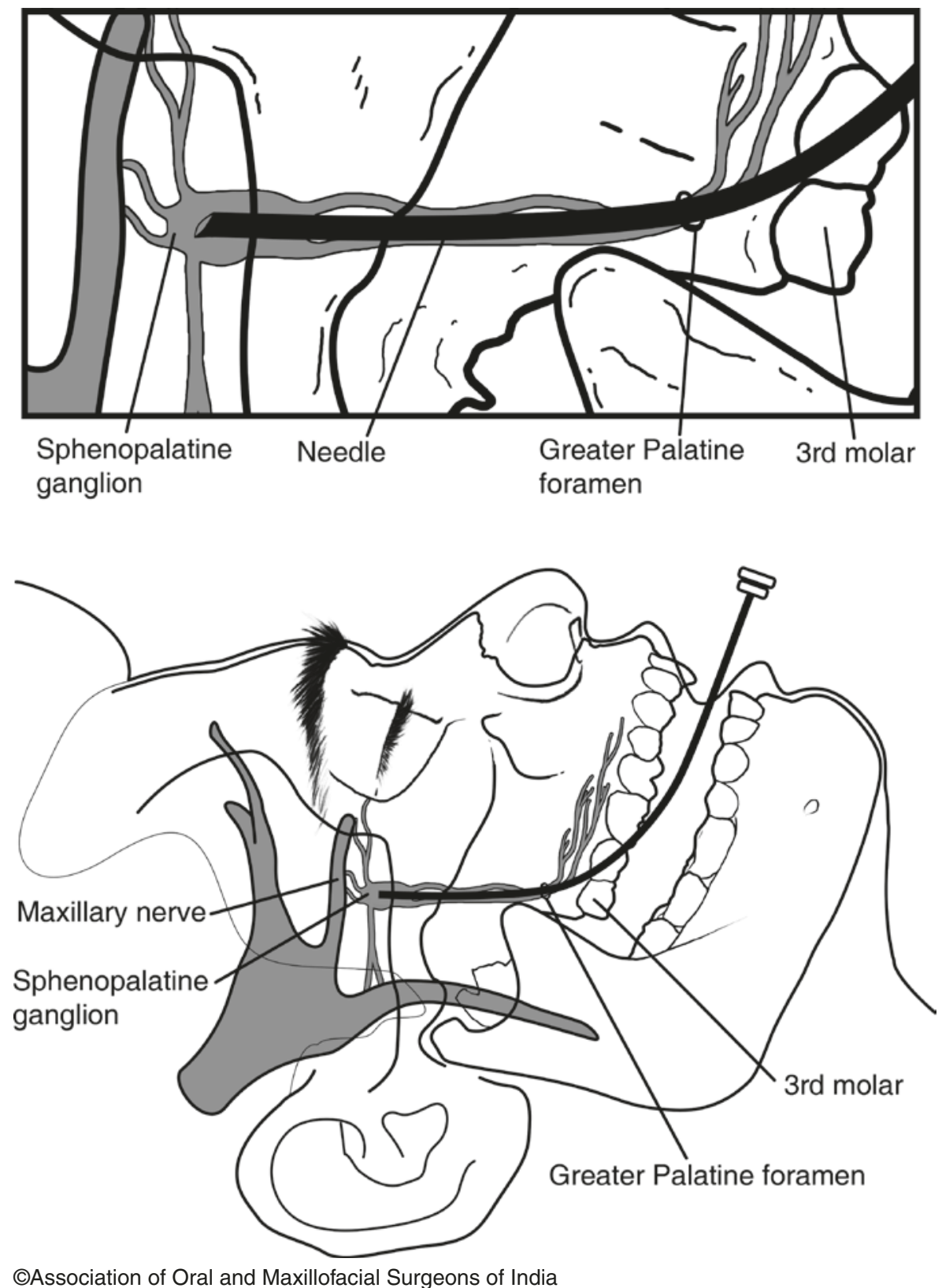

CAssociation of Oral and Maxillofacial Surgeons of India gate. It does not have a cord and it can be recharged. Dental vibe significantly lowered the self-reported pain during local anesthesia injections compared to a conventional approach.

\subsubsection{Accupal}

It is a cordless device, which shuts the pain gate by preconditioning the site of injection by pressure and vibration. To energize the dental tissue in and around the site to be punctured by the needle, Accupal incorporates the "Pain Gate theory" [40].

\subsubsection{C-CLAD (Computer-Controlled Local Anesthetic Delivery)}

With this device, there is a controlled delivery of the anesthetic and hence reduction of pain during injection. With this device, we can slowly administer anesthesia and control the injection speed [41].

\section{Advantages of C-CLAD device}

Higher success rates for single tooth anesthesia. The absence of pain especially in pediatric patient with disruptive behavior. More effective than a traditional syringe. 
Disadvantage-Difficulty in locating the precise site for needle placement.

$C$-CLAD technology led to the development of an instrument for medical and dental injections capable of controlling all variables of subcutaneous injection event.

\subsubsection{Compu-Flo}

Allows instantaneous real-time measurement of fluid exit pressure at the tip of the needle. This approach to fluid exit pressure at the tip of the needle is called dynamic pressuresensing technology (DPS) technology.

\subsubsection{STA—single tooth anesthesia}

More predictable, reliable, comfortable anesthesia than highpressure mechanical syringe. The system incorporates the safety of using dynamic pressure-sensing technology allowing low-pressure administration of local anesthetic drugs. All patients receiving PDL with STA device reported subjective pain responses of minimal or no pain.

\subsubsection{Jet Injection}

The principle of Jet injection is that the mechanical energy is used to force a thin column of the local anesthetic solution through a small opening into the soft tissue under pressure without causing tissue damage. There is less or no pain during this procedure [42].

\subsubsection{MED-JET H III}

Local anesthetic solution in extremely small amount is administered under pressure through an orifice seven times smaller than the smallest available.

\subsubsection{Safety Dental Syringes [43]}

The protective sheath over the needle prevents accidental needle stick injury.

\section{Ultrasafety Plus XL Syringe}

The plunger, which is autoclavable and reusable, has a sterile disposable protective shield. It does not have to be disassembled prior to disposal.

\section{Ultrasafe Syringe}

Transparent disposable syringe with retractable needle sheath is helpful in aspiration and helps in seeing the aspirated contents in the syringe barrel.

\section{Hyposafety Syringe}

Disposable syringe and needle, which is translucent with a retractable needle into the barrel. Hence, less chance of needle stick injury. The main disadvantage is that the needle cannot be re-exposed to readminister the remaining solution.

\section{REV VAC Safety Syringe}

It is similar to the standard conventional syringe, the difference being that when the plunger reaches the bottom after all the medicine has been administered, further push on the plunger will cause breakage of the needle, which retracts into the plunger. It can be used only once.

\subsubsection{Devices for Intraosseous Anesthesia [44]}

\section{Stabident}

This device can be used with the armamentarium that is available in the clinic to administer the anesthetic solution. The main disadvantage is that inaccessible areas cannot be anesthetized with this equipment.

\section{X-Tip}

It is a single-step method. An initial drill is placed, which allows entry and withdrawal in one step during administration.

\subsection{Conclusion}

Pain is always a deterrent to seek treatment and hence local anesthesia is a boon to all clinicians and patients alike. Although the medication provides pain relief, its administration has always instilled fear in one and all. The advances in equipment and techniques of local anesthesia administration have undergone continuous research and development to make it as painless as possible.

\section{References}

1. Ouchi K, Koga Y, Nakao S, Sugiyama K. Dexmedetomidine dose dependently enhances local anesthetic action of lidocaine. J Oral Maxillofac Surg. 2014;72:474.

2. Holmdahl MH. Xylocain (lidocaine, lignocaine), its discovery and Gordh's contribution to its clinical use. Acta Anaesthesiol Scand Suppl. 1998;113:8-12.

3. Howlader D, et al. Surgical management of mandibular subcondylar fractures under local anesthesia: a proposed protocol. J Oral Maxillofac Surg. 2019;77:1040.e1-9.

4. Burm AG, Van der Meer AD, Van Kleef JW. Pharmacokinetics of the enantiomers of bupivacaine following intravenous administration of the racemate. Br J Clin Pharmacol. 1994;38:125.

5. Chapman P. A controlled comparison of the effectiveness of bupivacaine for post-operative pain control. Aust Dent J. 1988;33:288.

6. Van Eeden SP, Patel MF. Prolonged paraesthesia following inferior alveolar nerve block using articaine. Br Oral Maxillofac Surg. 2002;40:519-20. 
7. Da Silva CB, et al. Anaesthetic efficacy of unilamellar and multilamellar liposomal formulations of articaine in inflamed and uninflamed tissue. Br Oral Maxillofac Surg. 2016;54:295-300.

8. Neal JM. Effects of epinephrine in local anesthetics on the central and peripheral nervous systems: Neurotoxicity and neural blood flow. Reg Anesth Pain Med. 2003;28:124.

9. Vempaty $S$, et al. Is lignocaine with out adrenaline a better choice for lip wounds crossing vermillion border? Int J Oral Maxillofac Surg. 2017;46:90-1.

10. Haasio J, Jokinen T, Numminen M, Rosenberg PH. Topical anaesthesia of gingival mucosa by $5 \%$ eutectic mixture of lignocaine and prilocaine or by $10 \%$ lignocaine spray. Br J Oral Maxillofac Surg. 1990;28:99-101.

11. Pere P, lizuka T, Rosenberg PH, Lindqvist C. Topical application of 5\% eutectic mixture of lignocaine and prilocaine (Emla) before removal of arch bars. Br J Oral Maxillofac Surg. 1992;30:153-6.

12. Svensson P, Kolsen Petersen J, Svensson H. Efficacy of a topical anesthetic on pain and unpleasantness during scaling of gingival pockets. Anesth Prog. 1994;41:35-9.

13. Gow-Gates G, Watson JE. Gow-Gates mandibular block: applied anatomy and histology. Anesth Prog. 1989;36:193-5.

14. Gaum LI, Moon AC. The ART mandibular block. Can J Dent Assoc. 1997;63:454-9.

15. Aggarwal V, Singla M, Kabi D. Comparative evaluation of anesthetic efficacy of GowGates mandibular conduction anesthesia, Vazirani-Akinosi technique, buccal-plus-lingual infiltrations, and conventional inferior alveolar nerve anesthesia in patients with irreversible pulpitis. Oral Surg Oral Med Oral Pathol Oral Radiol Endod. 2010;109:303-8.

16. Frangiskos $\mathrm{F}$, et al. Incidence of penetration of a blood vessel during inferior alveolar nerve block. Br Oral Maxillofac Surg. $2003 ; 41: 188-9$.

17. Jabar J. Should we be giving bilateral inferior alveolar and lingual nerve blocks for third molar surgery? Br Oral Maxillofac Surg. 2014;52:16-7.

18. Singh B. Mandibular nerve block for the removal of dentures during trismus caused by tetanus. Anesth Analg. 2006;103:252-3.

19. Kashyap VM, et al. Effect of alkalinisation of lignocaine for intraoral nerve block on pain during injection, and speed of onset of anaesthesia. Br Oral Maxillofac Surg. 2011;49:e72-5.

20. Vinay M. Int J Oral Maxillofac Surg. 2007;36:1031.

21. Milner QJ, Guard BC, Allen JG. Alkalinization of amide local anaesthetics by addition of $1 \%$ sodium bicarbonate solution. Eur J Anaesthesiol. 2000;17:38-42.

22. Gerbino G, et al. Management of needle breakage using intraoperative navigation following inferior alveolar nerve block. J Oral Maxillofac Surg. 2013;71:1819-24.

23. Akinosi JO. A new approach to the mandibular nerve block. Br J Oral Surg Oral Med Oral Pathol Oral Radiol Endod. 1977;15:83.

24. Haas D. Alternative mandibular nerve block techniques. JAMA. 2011;142:8S.

25. Martinez Gonzalez J, Benito BP, Fernandez FC, et al. A comparative study of direct mandibular nerve block and the Akinosi technique. Med Oral. 2003;8:143.
26. Gow-Gates GA. Mandibular conduction anesthesia: a new technique using extraoral landmarks. Oral Surg Oral Med Oral Pathol. 1973;36:321.

27. Malamed SF. Techniques of regional anaesthesia in dentistry. Handbook of local anesthesia. St. Louis, MO: Elsevier; 2013.

28. Stojcev Stajcić L, Gacić B, Popović N, Stajcić Z. Anatomical study of the pterygopalatine fossa pertinent tothe maxillary nerve block at the foramen rotundum. Int J Oral Maxillofac Surg. 2010;39(5):493-6.

29. Stajcić Z, Todorović L. Blocks of the foramen rotundum and the oval foramen: a reappraisal of extraoralmaxillary and mandibular nerve injections. Br J Oral Maxillofac Surg. 1997;35:328-33.

30. Kampitak W, Tansatit T, Shibata Y. A novel technique of ultrasound-guided selective mandibular nerve block with a lateral pterygoid plate approach: a cadaveric study. Reg Anesth Pain Med. 2018;43:763-7.

31. Dziadzko MA, Heritier F. Suprazygomatic access for continuous bilateral mandibular nerve block for pain and trismus relief in the tetraplegic patient. J Oral Maxillofac Surg. 2016;74:1947.e1-5.

32. Suresh S, Barcelona SL, Young NM, Heffner CL, Coté CJ. Does a pre-emptive block ofthe great auricular nerve improve postoperativeanalgesia in children undergoing tympanomastoid surgery? Anesth Analg. 2004 Feb;98(2):330-3.

33. Garg R, Singhal A, Agrawal K, Agrawal N. Managing endodontic patients with severe gag reflex by glossopharyngeal nerveblock technique. J Endod. 2014 Sep;40(9):1498-500.

34. Rao S, Rao S. Glossopharyngeal nerve block: the premolar approach. Craniomaxillofac Trauma Reconstr. 2018 Dec;11(4):331-2.

35 . Henthorn RW, et al. Which method for intraoral glossopharyngeal nerve block is better? Anesth Analg. 1995 Nov;81(5):1113-4.

36. Parameswaran A, Ganeshmurthy MV, Ashok Y, Ramanathan M, Markus AF, Sailer HF. Does sphenopalatine ganglion block improve pain control and intraoperative hemodynamics in children undergoing palatoplasty? A randomized controlled trial. J Oral Maxillofac Surg. 2018 Sep;76(9):1873-81.

37. Binfalah M, Alghawi E, Shosha E, Alhilly A, Bakhiet M. Sphenopalatine ganglion block for the treatment of acute migraine headache. Pain Res Treat. 2018;2018:2516953.

38. Roeber B, et al. Evaluation of the effects of the VibraJect attachment on pain in children receiving local anesthesia. Pediatr Dent. 2011;33(1):46-50.

39. Ching D, et al. Effect of the Dental Vibe injection system on pain during local anesthesia injections in adolescent patients. Pediatr Dent. 2014;36(1):51-5

40. Melzack R, Wall PD. Pain mechanisms: a new theory. Science. 1965 Nov 19;150(699):971-9.

41. Kwak EJ, et al. Computer-controlled local anesthetic delivery for painless anesthesia: a literature review. J Dent Anesth Pain Med. 2016;16:81-8.

42. Lambrianidis T, et al. Dental analgesia by jet injection. Br J Oral Surg. 1979-80;17:227-31.

43. Zakrzewska JM, Boon EC. Use of safety dental syringes in British and Irish dental schools. Br Dent J. 2003;195:207-9.

44. Feridoz J, Raj JD. Intraosseous anesthesia in dentistry - a review. Drug Invention Today. 2018;10:3035-40.

Open Access This chapter is licensed under the terms of the Creative Commons Attribution 4.0 International License (http://creativecommons. org/licenses/by/4.0/), which permits use, sharing, adaptation, distribution and reproduction in any medium or format, as long as you give appropriate credit to the original author(s) and the source, provide a link to the Creative Commons license and indicate if changes were made.

The images or other third party material in this chapter are included in the chapter's Creative Commons license, unless indicated otherwise in a credit line to the material. If material is not included in the chapter's Creative Commons license and your intended use is not permitted by statutory regulation or exceeds the permitted use, you will need to obtain permission directly from the copyright holder.

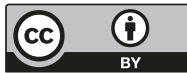

